\title{
Regulamentação da "Profissão": desejos e mal-estares ${ }^{1}$
}

\author{
Alexandre Fernandes Vaz ${ }^{2}$
}

\section{RESUMO}

O objetivo do presente texto é apresentar um : conjunto de reflexões, de caráter exploratório, : sobre a "Regulamentação da Profissão de: Educação Física". Procuro levantar algumas : dificuldades, implicações e decorrências, : desejos, motivações e mal-estares que se : relacionam à tese $e$ à aplicação da : regulamentação da profissão. Nesse contexto : discuto a relação dos "especialistas" com as : práticas corporais. Minhas considerações : apontam para a dificuldade em se limitar, sem : grandes prejuízos, o campo as práticas corporais : para os "profissionais de Educação Física". Defendo, por fim, a necessidade de um diálogo : mais aberto e menos entrincheirado sobre o: tema.

Palavras-Chaves: Regulamentação da Profissão; Práticas Corporais; Mercado de Trabalho em : Educação Física

\section{ABSTRACT}

The aim of this paper is to present some: exploratory reflections on the "Regulation of the Profession of Physical Education". I try to show up: some difficulties, implications and consequences, : desires, motivations and indispositions that link to: the thesis and the application of the regulation of: the profession. In that context I discuss the: specialists' relationship with the corporal practices. My considerations point for the difficulty in limiting, without great damages, the corporal practices for: the "professionals of Physical Education". I defend, : however, the need of more free dialogue on the: subject.

Key-words: Regulation of the Profession; Corporal Practices; Labor Market in Physical Education

\begin{abstract}
A sociedade contemporânea opera com vários vetores que se entrecruzam simultaneamente. Isso significa que valores e normas muitas vezes contraditórios coexistem nos mesmos processos, freqüentemente nas mesmas pessoas. Argumentos racionais com outros apaixonados, versões históricas com idiossincrasias, desejos, sonhos e aspirações expressam-se muitas vezes nos mesmos interlocutores.
\end{abstract}

A dinâmica histórica nos mostra esses movimentos contraditórios, e talvez esteja aí a grande dificuldade, mas também a grandeza, em se estudar os processos sociais em movimento. É preciso aprender, nesse sentido, que os fenômenos sociais nunca se apresentam de forma pura e independente, mas que possuem graus diferenciados de realização e expressão. Perceber isso nos livra dos maniqueísmos, mas nos coloca os desafios de estudar com mais cautela nossos objetos, sem os simplismos que separam o mundo em dicotomias.

Com isso não quero dizer, evidentemente, que não existem diferenças. Ao contrário, elas existem, e nosso desafio é justamente, de forma rigorosa e fina, diferenciar um fenómeno de outro, ou a forma como se apresentam. Precisamos ter cuidado e desenvolver instrumentos de investigação reflexiva adequados para analisar como e em que grau os fenómenos sociais se apresentam.

As reflexões que vou apresentar partem justamente do cuidado em refletir sobre uma questão bastante polémica, que ainda viceja no meio da Educação Física/Ciências do Esporte. Trata-se da "Regulamentação da Profissão", que tem gerado debates acalorados, mal-estares entre colegas, incompreensões e disputas acirradas. Limito-me - e 
20 contento-me - nesse texto, a levantar e trabalhar com " algumas hipóteses que possam ajudar o debate a * prosseguir.

Considero normal e desejável que existam posições : divergentes, que talvez correspondam, stricto senso, ao posicionamento que em geral, mas não sem : dissonâncias, as pessoas têm a respeito de outros : temas da educação e da sociedade em geral. Isso faz : parte do jogo democrático. Gostaria, no entanto, que : se criasse, mesmo na divergência, um clima de : entendimento, para que os debates acontecessem : em um ambiente um pouco mais respeitoso, no qual seja possível escutar os argumentos dos adversários, " para discuti-los a luz de mais cordialidade e, por que : não dizer, de racionalidade.

Mesmo com a lei que regulamenta a atuação do : "Profissional de Educação Física" em vigor, seguem : as discussões a respeito. Dada a virulência com que : ocorrem, suponho que os debates que a antecederam : não foram suficientemente abrangentes. Nesse : contexto ganha força em nosso meio, : indiscutivelmente mas não de forma monolítica, a : :ese da regulamentação da profissão. Procura-se, com * a denominação "profissional de Educação Física" : abarcar um campo de atuação que daria conta do : trabalho com todas as "atividades físicas". Alarga-se : assim o horizonte do que se compreende como um 'profissional da área". Passo nesse sentido fora dado : i há alguns anos, com a criação dos primeiros: bacharelados em Educação Física. Já há hoje, sentindo " e arendendo aos imperativos do mercado e das novas: Tendências da estrutura académica no Brasil, cursos : que. por exemplo, terão como mote central : especificidades bastante grandes, por exemplo, a : administração/gestão dos esportes.

Há um primeiro ponto que me incomoda muito na : regulamentação. Ele não se refere necessariamente : à tese em si, mas a motivação de fundo que nela : desemboca. Refiro-me à questão do "sacrossanto" : mercado, no qual se estrutura uma das mais profundas : raízes da regulamentação. Os profissionais de Educação : Física preocupam-se com seu mercado de trabalho, " e com isso entronizam-no como a razão de ser das : coisas, a mola propulsora da vida deles. Admitem : portanto que sua força de trabalho deve ser mesmo uma mercadoria a ser comprada e vendida, e procuram uma lei que regulamente esse processo de troca/exploração. Em outras palavras, legitimam, sem mais, a produção capitalista, uma vez que tornam o próprio trabalho sua figura primeira e essencial, a mercadoria. ${ }^{3}$ Parece não haver nada aquém ou além disso. Para legitimar essa servidão voluntária ${ }^{4}$, narcotizam-se com a idéia de que terão sua profissão respeitada, e/ou de que serão "empresários". Não sou tolo a ponto de dizer que não se pode relacionar com o mercado. $\mathrm{O}$ que me incomoda é a adesão pura e incondicional, desejosa. Repito, o que me perturba é essa servidão voluntária.

É curioso que frequentemente a união das "tribos", dos diversos grupos - sejam étnicos, políticos, religiosos, esportivos, ou de qualquer outro tipo - se dá por meio da eleição

de um inimigo comum, geralmente um outro grupo, que deve ser perseguido e exterminado. Foi assim, pelo menos em parte, no nazismo, nas ditaduras latinoamericanas e muitas vezes também nas Não sou tolo a ponto de dizer que não se pode relacionar com o mercado. $O$ que me incomoda é a adesão pura e incondicional, desejosa. Repito, o que me perturba é essa servidão voluntária. experiências do "socialismo real". Nesses e em outros processos político-sociais sempre houve um inimigo construído no imaginário social, que fez com que nas pessoas ressurgisse aquele sentimento de ódio e repulsa mais arcaico, mais tribal, mais atávico.

Não é muito diferente no processo de regulamentação da profissão. Para que possam dar forma a essa adesão, os educadores físicos ${ }^{5}$ procuram o seu outro, não como vetores do reconhecimento das diferenças, mas como inimigos, os "que não podem exercer a profissão". Eles estão divididos em dois grupos, os "de outra área" e os "leigos", tachados, entre outros adjetivos, de charlatões, "marombeiros" e irresponsáveis.

No primeiro grupo estão várias figuras académicas, principalmente o fisioterapeuta, mas também - entre 
outros, mas sempre dependendo da relação de forças : -, o médico, o historiador, o antropólogo, o psicólogo : ou o administrador. É interessante que o "inimigo" " apareça, pelo menos desde meus tempos de : graduação, com a cara do fisioterapeuta, uma profissão : da área da saúde, freqüentemente vista como : subordinada à medicina. Digo isso porque é por aí, : como área da saúde subordinada à medicina, mas : sem necessariamente atacar o médico, com o qual se : procura forte identificação/vinculação, é que passa a * legitimação do "profissional" da Educação Física, o " que sem dúvida provoca decorrências e nos coloca : impasses.

O outro "agrupamento inimigo" é o dos leigos. Há : uma tentativa de acordo com eles, um pacto de " transição, que os habilita para certas atividades, para as quais se dedicam a algum tempo. $\mathrm{O}$ acordo também vale para aquelas áreas que não são contempladas : nos cursos de formação profissional. No fundo é " contra eles que os da Educação Física querem se defender, porque "roubam" nosso espaço profissional, estão nas academias, nas escolinhas de esportes, nos : clubes, nas empresas de recreação. Muitos lamentaram ter havido a necessidade de incorpora-los, em * princípio, ao CONFEF. Em geral dizemos que nosso " objetivo é proteger a sociedade da ação desses sem " formação, mas esse é um argumento que não se " sustenta, como veremos logo mais.

Considero absolutamente questionáveis os : argumentos em favor da regulamentação, quando : eles elegem os "inimigos". Os motivos para isso se " concentram, a meu modo de ver, em um grande : aspecto, que é o lugar que o corpo e as práticas : corporais ocupam não só em nossa sociedade, mas " em várias culturas. As práticas corporais são objetos : de trabalho eminentemente multidisciplinar, e me : parece difícil delimita-las, sem enorme prejuízo, em : um campo que seja exclusivo dos profissionais de Educação Física. Note-se, por exemplo, que o Estatuto : do Conselho Federal de Educação Física, O Estatuto : do CONFEF pode ser encontrado no site : http://www.confef.org.br/. em seu artigo 10., diz : que compete ao Profissional de Educação Física : desde organizar, supervisionar e ensinar no: sentido da educação corporal, até elaborar " projetos, pesquisar éministrar cursos nas áreas de atividade física e desportiva. :

Há dois problemas graves no artigo 10., que de certa maneira constitui o cerne do Estatuto. O primeiro é excluir do trabalho com as práticas corporais Utilizo a. expressão práticas corporais ${ }^{1}$ um sem número de profissionais que trabalham com elas, mas que poderiam não se adequar ao artigo 14, que diz quem pode e quem não pode ser "profissional" de Educação Física. Refiro-me a pessoas como Ismael Ivo, coreógrafo brasileiro que atua há muitos anos no exterior (que não fosse o fato de lá viver estaria, quem sabe, em "ilícito pessoal", segundo o artigo 18 dos Estatutos do CONFEF), a Antônio Henrique Vianna, cardiologista que atua como técnico internacional de atletismo, Telê Santana, Valdir Espinosa, terapeutas corporais em geral, gente de teatro, Mestre Nô e todos os outros grandes da capoeira, enfim, pessoas envoltas em uma tradição cultural - acadêmica ou não - que passam a ser deslegitimadas em seus saberes. Como defender que eles não têm legitimidade para trabalhar com as práticas corporais que desenvolvem e orientam?

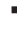
É por isso indefensável a tese de que alguém não pode ser treinador de um esporte porque não se graduou em Educação Física. A dinâmica dos esportes mostra que é preciso conhecer bem a cultura do campo específico, sua dinâmica própria, e que muitas vézes a experiência na modalidade vale muito. Talvez sëja pouco importante, para um treinador, a graduação em Educação Física, e por isso em muitos países as féderações esportivas mantêm seus próprios cursos de formação e seus testes para o enquadramento dos tṛieinadores em categorias.

-

Mais importante que a formação em Educação Física sẹria conhecer algumas disciplinas ou sub-disciplinas, cọ̉mo a biomecânica, a psicologia, a fisiologia, e a netodologia do treinamento, além, é claro, de um profundo conhecimento da dinâmica sócio-cultural dä modalidade. Para isso é possível e mesmo nécessário buscar conhecimento em outros campos do universo acadêmico. Mais vale isso do que cursar sémestres seguidos de disciplinas que pouco terão a ver com o trabalho profissional propriamente dito. Së permanecemos no campo acadêmico, acredito que

- 
um mestrado em treinamento esportivo faça mais .: sentido na formação de quem esteja interessado no :.: assunto, desde que aberto a qualquer profissional :interessado, de qualquer área. ${ }^{8}$

Nesse contexto há ainda um outro ponto. Como :. proibir pessoas das várias áreas de conhecimento que :. estudam as práticas corporais, que não pesquisem :sobre o tema, sob pena de serem perseguidas por:.: exercício ilegal da profissão? Imagine-se, como:.: exercício, que Pierre Bourdieu é brasileiro, e aí como ": não professor de Educação Física, estaria impedido :" de exercer a profissão, e portanto de pesquisar sobre:.: esportes. Por que não pensar em farmacêuticos, :.: bioquímicos, médicos, antropólogos, nutricionistas, ": psicólogos, sociólogos, historiadores e fisiologistas, :entre outros, que estudam as práticas corporais sob:.: diferentes aspectos, oxigenando o debate e a reflexão? :

No mundo acadêmico que trata do esporte - :" vastíssimo, multifacetado - é muito grande o número :. de pesquisadores que não vêm da formação em :" Educação Física. Aliás, boa parte dos grandes trabalhos, :" com diferentes abordagens teóricas, é fruto do esforço :. de sociólogos, antropólogos, fisiologistas, etc, para :-. s quais os grandes periódicos internacionais não :perguntam se são ou não filiados a um conselho :" profissional.

Qual periódico sério vai se importar, ao receber um ". paper no campo da Fisiologia do Exercício ou da :. -História do Esporte, se o autor ou autora é filiado ... ao

CONFEF? Esse procedimento, sobretudo no campo :da pesquisa, num momento no qual as barreiras :.. disciplinares caem, deveria ser considerado crime :de lesa epistemologia!

jostaria de retomar uma questão, indicada um pouco "ais acima. Essa limitação desconsidera que há práticas :. corporais envolvidas em outras tradições, que não :.: necessariamente são acadêmicas. Um mestre de :.: capoeira, ou em alguma das lutas asiáticas, é formado :em uma tradição diferente daquela da Universidade, : embora possa se relacionar com ela. Há um conjunto :de normas, de valores, de regras, de procedimentos :-. r....::g:cos, em uma palavra, de saberes, cuja ::.".iizagem e incorporação se dá por outras vias :-: que concorrem com o saber acadêmico e universitário. Desrespeitar isso é aniquilar uma tradição cultural.

Pessoalmente defendo o saber acadêmico e científico. Apesar de ser um crítico da ciência e da tecnologia tal como as levamos a acontecer, sei que certamente a vida seria ainda mais dura e penosa, como já foi um dia, sem os ganhos que nos proporcionou a ciência. Considero ainda que a ciência pode ser um antídoto contra o obscurantismo e os vários misticismos que ganham força entre nós, até mesmo no ambiente universitário. Ao mesmo tempo não deixo de considerar o caráter destrutivo da ciência, e a forte tentação que é transforma-la em uma nova forma de mistificação, processos inscritos na própria raiz da racionalidade ocidental. Não posso, portanto, concordar com a entronização da ciência como medida de todas as coisas, principalmente quando ela, em sua soberba, desconsidera outros saberes.

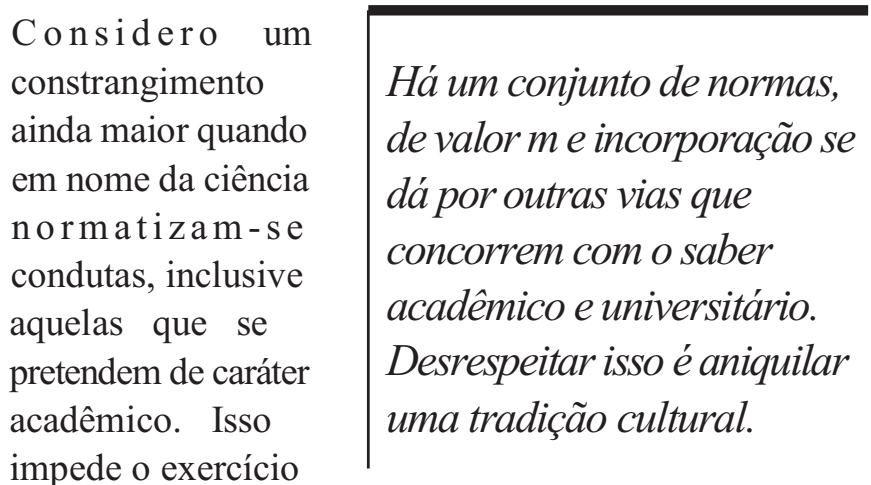
autocrítico da ciência, sem o qual ela não pode avançar. Por isso o espanto quanto se lê no artigo 47. dos Estatutos, inciso II, que cabe a Comissão de Legislação e Normas do CONFEF "estudar a questão da cientifização da Educação Física, de suas várias vertentes e denominações". A coisa vai tão longe que o CONFEF pretende até mesmo, "funcionar como órgão consultivo dos poderes constituídos em assuntos relacionados à Educação Física, ao exercício de todas as atividades e especializações a ele pertinente, inclusive no ensino e pesquisa em qualquer nível." (Art. 6., X). O CONFEF desconsidera com isso a dinâmica da produção acadêmica, que não passa - ou pelo menos não deve passar - pelo corporativismo, mas pelas entidades científicas, como o Colégio Brasileiro de Ciências do Esporte (que tem assento na Sociedade Brasileira para o Progresso da Ciência) 


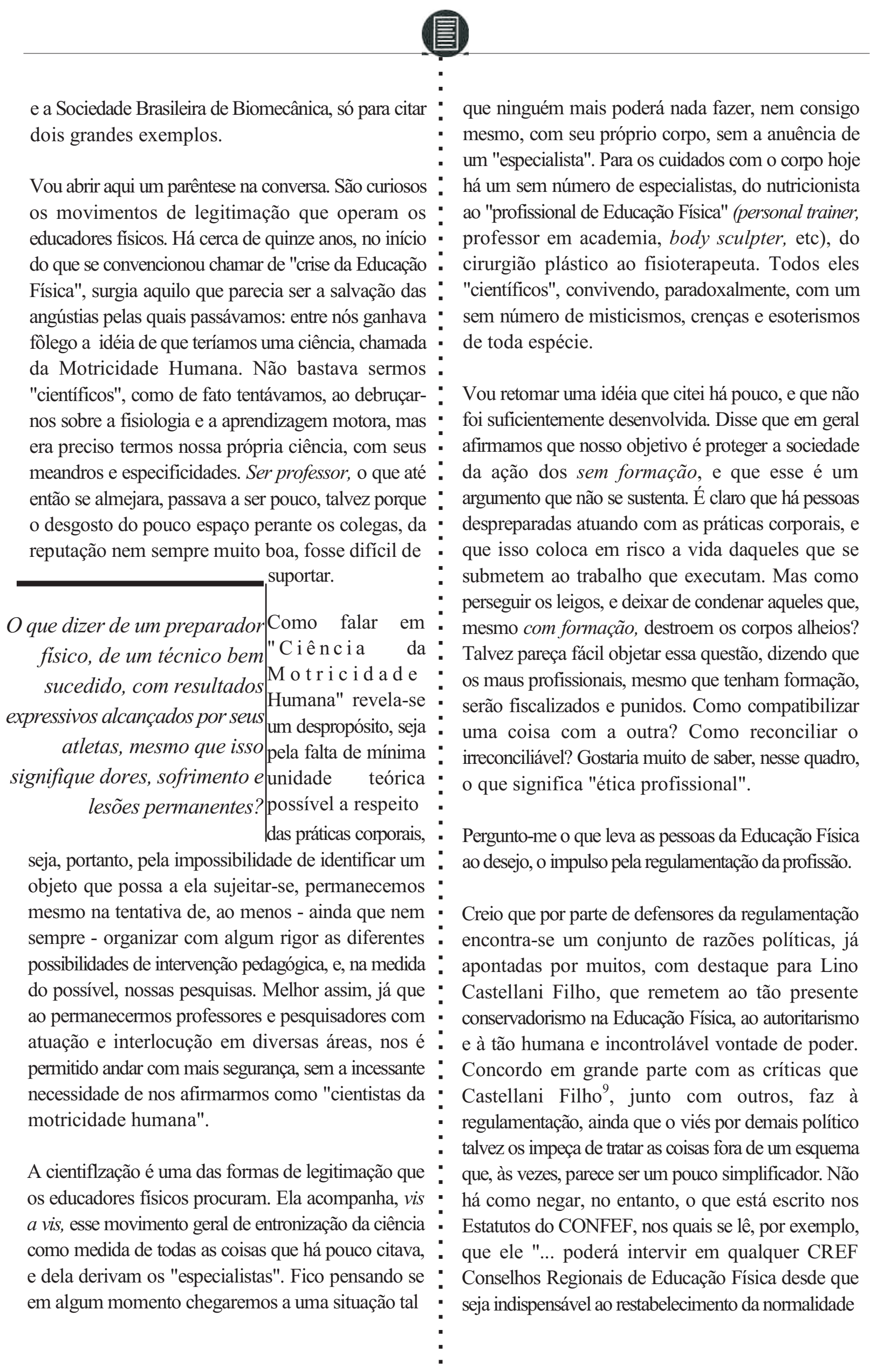


administrativa ou financeira ou a garantia da efetividade : do princípio da hierarquia institucional." (Artigo 52.). " Impossível não comparar com os discursos das : ditaduras, em particular as latino-americanas, : preocupadas em restaurar a "ordem", a "normalidade" . e acabar com a "anarquia". Nossos generais-presidentes e seus ministros foram expertos em manejar armas, : palavras e instrumentos de tortura para "restabelecer: a ordem e a hierarquia". ${ }^{10}$

Acredito que haja duas grandes decorrências da : regulamentação, que são ao mesmo tempo motivos : pelos quais se luta por ela. A primeira que observo é * que de fato há um aumento na auto-estima dos : educadores físicos, ainda abalada pelos papéis : secundários exercidos, seja nas escolas, nos esportes : convencionais ou nas academias.

Nas escolas são, como disse acima, muitas vezes : desrespeitados pelos outros professores, coordenadores e diretores, que freqüentemente * enxergam a Educação Física como atividade de : ocupação do tempo, "liberação de energia", ou : qualquer coisa semelhante ${ }^{11}$. Nas academias nem : sempre os clientes (e as clientes) se preocupam se o : professor é ou não graduado, mas se é "cativante", : "carismático", se tem o corpo esculpido - porque há : de ser um espelho para alunos e alunas, que devem, : por seu corpo, admirá-lo, invejá-lo, desejá-lo -, se * explica e corrige bem os movimentos técnicos.

Mesmo nos esportes convencionais essa espoliação " moral freqüentemente está presente, uma vez que : muitas vezes o saber acadêmico é desvalorizado em : favor da experiência vivida, por exemplo, pelos : boleiros.

A regulamentação da profissão dá um novo ânimo, : parece que os educadores físicos vêem nela a : oportunidade de por a cabeça fora da água e dizer, : "Aqui estamos nós", regulamentados, no nosso campo, : com nosso grupo, nossas atividades.

É, no entanto, uma legitimação pela janela, e talvez : nem mesmo mereça ser chamada como tal, uma : identidade que ganha força apenas no sentido : corporativo. É triste que precisemos disso para que : nossa auto-estima seja reforçada. Lamento também que nossa capacidade acadêmica - para além dos preconceitos - seja ainda frágil, e insuficiente para que possamos partilhar da mesa dos bons comensais da produção acadêmica.

Lamento sobretudo porque essa frágil e irracional (no sentido de meramente apaixonada) tentativa de legitimação profissional atinge em cheio nossa atuação na escola. Quando se fala em "profissional de Educação Física", está embutido um preconceito que já há tempos traz mal-estar. É aquele que desqualifica a Educação Física escolar, diminuindo o trabalho pedagógico com as práticas corporais nos ambientes educacionais. Note-se que a defesa e a propaganda da regulamentação pouco se ocupa da escola, preocupada que está com o mercado, cuja promessa mais sedutora é a transformação do "profissional" em "autônomo", em "empreendedor". A desqualificação do trabalho pedagógico escolar em detrimento de outras ocupações, é talvez não exatamente uma A desqualificação do trabalho decorrência, mas uma ${ }_{\text {das }}$ mais fortes pedagógico escolar em .expressões coexistem junto regulamentação profissão $^{12}$.. $^{2}$

Gostaria ainda de que detrimento de outras à ocupações, é talvez não da exatamente uma decorrência, mas uma das mais fortes expressões que coexistem junto fazer, para encerrar, mais à regulamentação da uma ponderação. Muitas profissão.

vezes o campo daqueles

que são contrários à regulamentação normalmente postado mais à esquerda no espectro político - é taxado de sectário e intolerante. Concordo que as manifestações de alguns grupos ou pessoas contrários à regulamentação são por vezes motivadas pela sedução das palavras de ordem, algo com o qual não simpatizo. Não se pode negar, no entanto, que o mecanismo que estigmatiza os contrários à regulamentação é mitológico, já que este campo costuma lançar-se ao debate de idéias, publicando/publicizando suas idéias e, mais do que isso, preocupando-se freqüentemente em entender, refletir e debater os argumentos de 
seus adversários. Procura portanto, ao contrário do que diz o mito, participar da discussão, uma vez que considera os argumentos do outro. Isso significa que : ele valoriza o debate. Também faz parte desse mito dizer que os críticos da regulamentação são contrários à Área de Educação Física/Ciências do Esporte, ou que negam, muitas vezes de forma irresponsável, qualquer tipo de controle no campo das práticas corporais. Gostaria de ver nos defensores da regulamentação da profissão a mesma disposição para crítica, a mesma vontade de escutar, analisar e debater os argumentos de seus adversários. Gostaria também que evitassem o recurso ao mito, para que não confundam os que procuram se inteirar do debate. Resta esperar e torcer para que façam isso.

\section{REFERENCIAS BIBLIOGRÁFICAS}

CASTELLANI FILHO, Lino. Teses acerca da questão da regulamentação da profissão. In: Política Educacional e Educação Física. Campinas: Autores Associados, 1998, p. 83-93.

COLETIVO DE AUTORES. Metodologia do ensino de Educação Física. São Paulo: Cortez, 1992.

CONSELHO FEDERAL DE EDUCAÇÃO FÍSICA Estatuto, http://www.confef.org.br/, 30/01/2001.

LA BOÉTIE, Etiene de. Discurso da Servidão Voluntária. 3. ed. São Paulo: Brasiliense, 1986. (Tradução de Laymert Garcia dos Santos)

LOVISOLO, Hugo. Educação Física: a arte da mediação. Rio de Janeiro: Sprint, 1994.

VAZ, Alexandre Fernandez. Aprender a produzir e mediar conhecimentos: um olhar sobre a prática de ensino de Educação Física. Motrivivência Elementos teórico-metodológicos para o ensino de Educação Física. Florianópolis, Editora da UFSC, Ano XI, n. 13, Novembro/1999, p 9-34.

\section{NOTAS}

${ }^{1}$. Este texto foi a base para minha exposição na Mesa "Efeitos da Educação Física após a Regulamentação da Profissão", na X Semana de Ensino, Pesquisa e Extensão - Educação Física no limiar do Século XXI, Curitiba, 25/10/2000. Apesar de alguns ajustes, ele mantém o espírito da fala, bem como o tom oral na redação. Algumas dessas ideias foram também debatidas no I Seminário Amapaense de Políticas Públicas para Educação Física, Esporte e Lazer, realizado em Macapá, Amapá, entre 4 e 7/11/1999. Agradeço aos organizadores desses eventos a gentileza do convite e a generosa acolhida.

2. Mestre em Educação pelo PPGE/UFSC; Professor Assistente do Centro de Ciências da Educação da Universidade Federal de Santa Catarina, onde trabalha com a graduação e pós-graduação em Pedagogia e Educação Física; Doutorando junto à Faculdade de Ciências Humanas de Sociais da Universidade de Hannover, Alemanha, onde é bolsista da CAPES . Endereço Profissional: MEN/CED/UFSC Campus Universitário, Caixa Postal 476 , Florianópolis - SC CEP: 88040-900. E.mail: alexvaz@ced.ufsc.br.

- 3 . Note-se que essa é uma ideia de resto largamente disseminada, uma vez que não se discute mais a possibilidade, ou pelo menos o desejo, de se superar o universo da exploração do trabalho. Em lugar disso coloca-se a busca do pleno emprego, que, por outro lado, é em si mesma contraditória com o modelo de vida capitalista.

4. Utilizo aqui, com alguma liberdade, a expressão consagrada de La Boétie (1986)

5. Tomo aqui por empréstimo a carinhosa expressão de Hugo Lovisolo (1994).

6. O Estatuto do CONFEF pode ser encontrado no site http://www.confef.org.br/.

' 7 . Utilizo a expressão práticas corporais por parecerme mais adequada que atividades fisicas. Corpo em lugar de físico não é uma opção meramente estilística, mas conceituai, já que a segunda expressão remete principalmente à mudança de posição, deslocamento, enquanto que a primeira envolve a expressão das histórias e tradições no corpo, dotado portanto de significados e experiências. A propósito, considero práticas corporais uma expressão teoricamente próxima de cultura corporal (Coletivo de Autores, 1992), conceito que me parece instigante e bastante significativo no entendimento da dimensão corporal da realidade.

8. Defendo de maneira organizada essa idéia desde pelo menos 1992, quando escrevi um texto que serviu de base para uma fala no curso de Especialização em Educação Física Escolar do CDS/UFSC. O texto, que permanece inédito, intitula-se Algumas Anotações sobre o Treinamento Desportivo na Modernidade. 
${ }^{9}$. Castellani Filho (1992).

:10. Para não ficar apenas nos textos acadêmicos, sugiro a leitura de Gabriel Garcia Marquez e de Júlio Cortázar, quando tematizam as ditaduras latinoamericanas.

${ }^{11} .0$ senso comum presente também na escola diz que a Educação Física tem para si, entre outras tarefas, a de "descontrair" as crianças e adolescentes, recreálos, ou ainda "liberar suas energias" acumuladas em sala de aula. Isso deve ser feito, nos diz o imaginário da escola, para que depois eles voltem para a sala, talvez mais calmos. Embora muitos afirmem que os alunos e alunas voltam, às vezes, ainda mais agitados, o discurso permanece. Note-se que esse discurso não é muito diferente daquele que sustenta a atividade física \& saúde, preocupada, entre outras coisas, em "tirar o stress".

${ }^{12}$. Afirmo isso no quadro de uma reflexão mais ampla, que pode ser acompanhada em Vaz (1999). 